\title{
A mixed integer linear program for an integrated fishery
}

\author{
MB Hasan* JF Raffensperger ${ }^{\dagger}$
}

Received: 25 October 2005; Revised: 10 January 2006; Accepted: 11 January 2006

\begin{abstract}
In this paper fishing trawler scheduling and production planning for a quota-based integrated commercial fishery is modelled mathematically. The catch capacity of fishing trawlers and the capacity of processing firms are two major factors which influence the scheduling of fishing trawlers. Production planning in fish processing firms depends on steady supply of fresh fish from the fishing trawlers to the processing firms. We develop a mixed integer linear programming (MILP) model to co-ordinate trawler scheduling, fishing, processing, and labour allocation of quota based integrated fisheries. We demonstrate the workability of our model with a numerical example and sensitivity analysis based on data obtained from one of the major fisheries in New Zealand.
\end{abstract}

Key words: Mixed integer linear program, fishing, trawler scheduling, processing, quotas.

\section{Introduction}

At approximately 2.5 million squire kilometres of ocean, ranging over 30 degrees of latitude, New Zealand's main exclusive economic zone (EEZ) is the fourth largest in the world and is fourteen times larger than its land mass. The fishery industry makes an important contribution to New Zealand's economy and is the fourth largest foreign exchange earner, worth NZ $\$ 1.7$ billion in 2004 . Around 26000 people are directly or indirectly employed in the fishery industry (New Zealand official yearbook, 2004/05).

To maintain and improve these fisheries resources and their utilization, activities such as fishing, trawler scheduling, processing, and marketing are important. Each of these activities depends on the others. For example, production planning in a fish processing firm depends on a steady supply of fresh raw material from the fishing fleets. Also, to promote fresh fish and top quality frozen fish to the consumer, the raw material has to

\footnotetext{
*Corresponding author: Department of Management, University of Canterbury, Private Bag 4800, Christchurch, 8020, New Zealand, e-mail: b.hasan@mang. canterbury.ac.nz

${ }^{\dagger}$ Department of Management, University of Canterbury, Private Bag 4800, Christchurch, 8020, New Zealand.
} 
be delivered to the processors and thereafter to the consumer in top quality condition. Trawler scheduling for fishing and landing plays an important role. For these reasons, there has been growing recognition that fisheries have to be viewed as a total system from the fish in water to the fish on the plate. This system includes fishing, trawler scheduling, processing, labour allocation, quota allocation, and marketing. A mathematical model which addresses trawler scheduling, processing plans, labour allocation that could be updated with information and run periodically, would aid in the decision making process. In this paper, we develop a MILP model for fishing trawler scheduling and production planning in an integrated commercial fishery of New Zealand. The aim of this model is to give a complete idea to the manager of a fishery about when and where a trawler should go for fishing, how much raw material should be landed, how much product should be produced, and how much regular and overtime labour hours are required. The end-effectsof-planning-horizon due to variability of catch rate and ways to deal with them are also discussed.

The remainder of the paper is organised as follows. In $\S 2$ we present a detailed literature review. In $\S 3$ we give a numerical illustration of the model. The model is presented in $\S 4$ and some output of a numerical example is shown. In $\S 5$ we present a sensitivity analysis on different decisions and we conclude the paper with some final remarks in $\S 6$.

\section{Literature Review}

In this section, we review the existing research in (i) fishing fleets and processing, (ii) co-ordination of fishing and processing and (iii) quota allocations.

\subsection{Fishing fleets and processing}

Most of the related literature includes models of the fluctuating fish stock, i.e. developing population-level models. However, this notion is not included in this paper. There are a few papers that deal with the fishing fleet. For example, Jensson (1981) presented a simulation model which analyzed fleet operation and congestion problems. The author discussed the effect of fleet operations on the total catch, on the utilization of different factories and on the different size categories of boats. Jensson (1982) presented a fleet mix model describing the fishing fleet, vessel mix and vessel allocation.

Digernes (1982) adopted an analytical approach for single vessel operations. The author expressed revenue as a function of the operations of the vessel depending on fishing time, amount of fish gear used per fishing day, catch per unit gear used and fish price. The various cost components were associated with operational factors. For example, fuel costs were expressed as a function of engine power and operating time.

However the above mentioned papers model only trawler operation for fishing, not scheduling of trawlers. Production planning at fish processing firms is a typical product mix problem. Mikalsen and Vassdal (1981) developed a multi-period LP model for one month production planning. The authors discussed a monthly production planning model for smoothing the seasonal fluctuations of fish supply. Their model was market-driven and incorporated the acquisition of raw material purchased, rather than acquired with their 
own fishing fleet. Jensson (1988) developed a product mix LP to maximize profit over a five day horizon of an Icelandic fish processing firm. The model determined product mix and labour allocations. The paper analyzed the production planning, market fluctuations and randomness of raw materials for fish processing firms. The author discussed his experience of real life testing. The model had approximately 160 variables, 80 restrictions and about 60 simple upper bounds.

\subsection{Co-ordinating fishing and processing}

Finding the fishing schedule and processing separately may lead to suboptimization of the total system, because processing depends on a steady supply of raw material from the fishing fleets to the processing firms. Jensson (1990) proposed a mixed integer linear program to solve the co-ordinated scheduling problem of trawler landings and plant operations. The paper does not consider the trawler scheduling problem. However, the production manager of a fish processing firm needs an initial schedule for trawler landings, along with the amount of raw material that each trawler lands. Gunn et al. (1991) studied tactical planning for a Canadian company with integrated fishing and processing. The authors formulated an LP to determine the product mix so as to maximize profit. The model included a fleet of trawlers, a number of processing plants and market requirements. Their model ignored the short-term trawler scheduling problem, the stochastic nature of operations, and the quality-time relationship which affects the value of fish products. Millar and Gunn (1992) developed a two-stage procedure for planning marketing and fishing activities for fish processing firms. Randhawa (1994) integrated an LP and a simulation for co-ordinating fishing and processing. He determined a trawler's fishing schedule and generated the quantity of catch during the fishing trip using a simulation model. He used an LP to determine the allocation of raw material and labour, mix of products, and inventory of raw material.

\subsection{Quotas}

To control the continuous decrease in fish supplies, the Icelandic government introduced quota regulation in 1984, and implemented it for nine main commercial species. This system was implemented for all commercial species in 1990. In 1986, New Zealand was the first country to use quotas on a broad scale in a multi-species fishery. Currently, this program applies to 32 species in 10 management areas of New Zealand. Other countries that use individual transferable quota systems include Australia, Canada, Italy, the Netherlands, Japan and South Africa. Helgason and Olafsson (1988) presented a deterministic decision support system for long and short term fisheries management of Icelandic fisheries. The authors considered the boat type and size for fishing, temporary bans, mesh size regulations, and the catch quota allocation. They also calculated the earnings and costs in the fisheries. The model computed the expected catch, economic outcome and other statistics on a year by year basis for 10 years. However, they kept the fishing fleet, and the recruitment constant. 


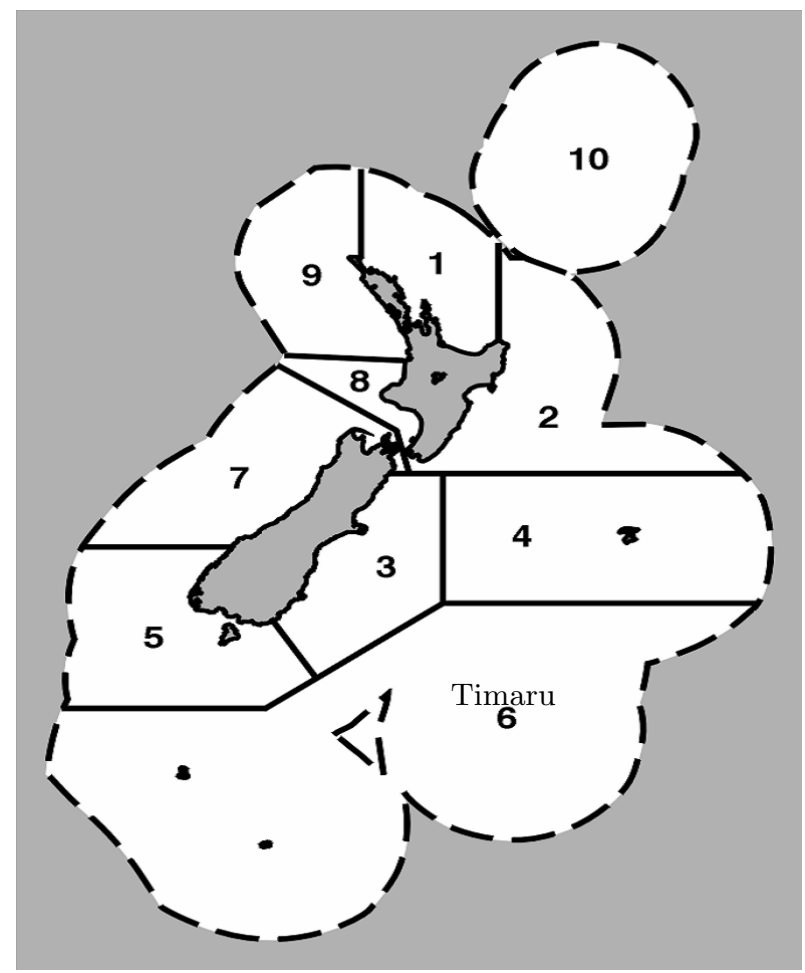

Figure 1: Exclusive Economic Zone of New Zealand.

\section{Problem situation}

We collected data from one of the major fisheries in New Zealand. The fishery has two small trawlers and one large trawler. Average expected catch for small vessels is 12 tons per day and takes two to three days per fishing trip. The average expected catch for the large vessel is 90 tons per day and takes up to 7 to 8 days per trip. The trawlers harvest 8 species over the year. In the running season, the trawlers harvest hoki, roughy, dory, ling, red cod, squid, barracouta and elephant fish. The company produces 10 different products over the year. The fish that cannot be processed during a period remain in inventory and are available for the next period production. Similarly, the product that cannot be sold during a period remains in inventory and will be sold in the next period. To allow proper testing of the model, we use some estimated numbers (for example, $F R_{i, l}$ denotes the fraction of different raw materials classified according to their quality).

In the following four subsections, we describe trawler scheduling, processing, and labour allocation.

\subsection{Trawler scheduling}

A trip of a fishing trawler is the movement for the purpose of fishing of the trawler from any landing port to a distinct fish stock and again from that stock to the landing port. To illustrate a trawler's trip, we show 10 species areas in the 200 miles exclusive economic zone of New Zealand, in Figure 1. For example, if a fishery is located at Timaru, then a 
trip can be defined as the distance travelled from Timaru to any fish stock area (say stock area 6 ), and returned from that stock to the fishery.

The start and end points of the trawler scheduling in our model are at the processing plant. The distance between the fishing ground and the processing plant may differ to a large extent and may impact catch preservation aspects and fuel capacity considerations. The trawler operating costs per period include the salary of the crew, diesel cost, and the average maintenance of each trawler. These costs vary according to the trawler class. Since the company owns the trawlers, the company pays the crew of the trawlers a salary. Since the trawler operation cost is fixed, we may assume that the landing price that the fishery pays to each trawler for each species and period is zero.

\subsection{Processing}

The processing of the fish caught by trawlers at sea usually involves chilled storage of the fish in crushed ice until the vessel returns to the port. When the trawler arrives at the freezing plant, the fish are inspected and graded by size and quality. The fish are unloaded, transported to the processing plant, and then processed according to the type and quality of the fish. At the plant, processing operations include cleaning, cutting, filleting, wrapping, skinning, forming, coating, grinding, drying, packing, and freezing. Major products include filleted, gutted, headed and gutted, dressed, fish sticks, fish blocks, etc. Heads, offal, etc. from the fish are converted to fish meal in some plants. The processing steps of different products are shown schematically in Figure 2.

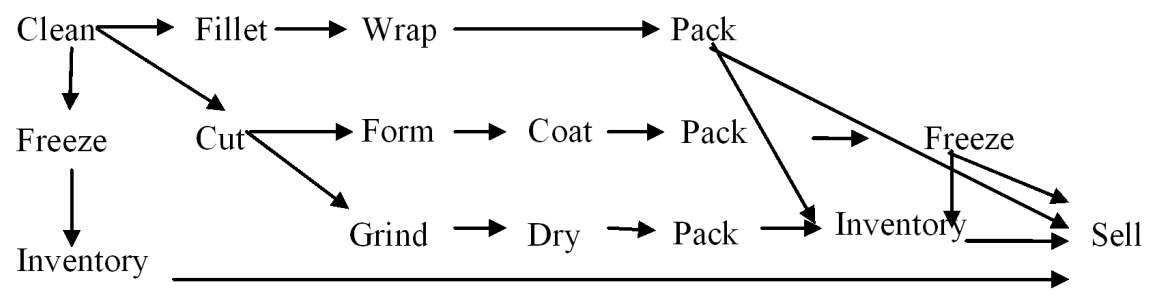

Figure 2: Processing steps of different products.

\subsection{Labour allocation}

We obtained data from the fishery regarding required labour hours per kilogram of product in different work centres for all raw materials and products, the wage rate for regular and overtime labour hours, lower and upper limits of the available labour hours, lower and upper limits of the available overtime labour hours, and the available machine hours for this fishery. Employees may work in any work centre. 


\section{Mathematical model}

In this section, we present our mixed integer linear programming (MILP) model to coordinate fishing, processing, quota allocation and labour allocation for an integrated commercial fishery. Relevant papers discussed in $\S 2$ which may complement our ideas include the multi-period LP model of Mikalsen and Vassdal (1981) for one month production planning, the product mix LP model of Jensson (1988) to maximize profit over a five day horizon of an Icelandic fish processing firm, and the tactical planning model of Gunn et al. (1991) for calculating the total profit of a Canadian company with integrated fishing and processing.

We mention several differences between our formulation and the papers mentioned above. The multi-period LP model of Mikalsen and Vassdal (1981) was market-driven and incorporated the acquisition of raw material purchased, rather than acquired with their own fishing fleet. The product mix LP model of Jensson (1988) addressed labour allocation for processing firms but did not address any fleet-specific issue or the issue of quotas. The tactical planning model of Gunn et al. (1991) included a fleet of trawlers, a number of processing plants and market requirements. However, their model ignored trawler scheduling and labour allocation in the processing firm. Also all of the papers discussed in $\S 2$, did not take into account trawler scheduling. Since production in processing firms depends on the steady supply of raw materials from the fishing fleet, and to do so the trawler scheduling plays an important role, it is important to develop a model to address fishing trawler scheduling and processing. None of the above mentioned papers addressed trawler scheduling, processing and labour allocation comprehensively. In our MILP model, we model quota-based integrated fishery's fishing trawler scheduling for fishing, processing and labour allocation.

We define a number of indices, parameters, and decision variables separately according to fishing trawler scheduling, processing and quota allocation in Tables 1-4.

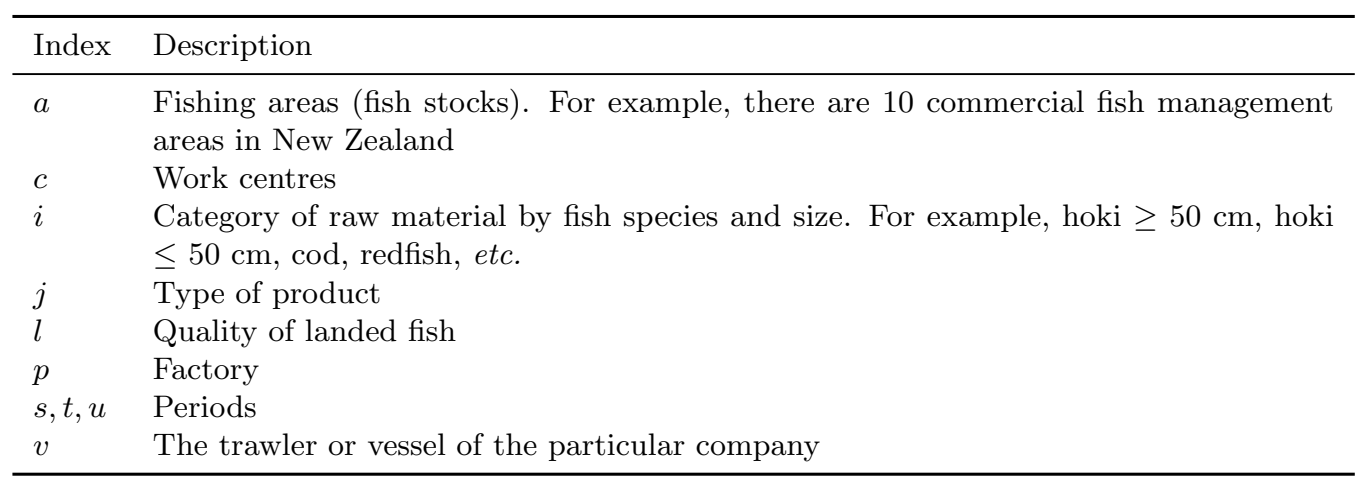

Table 1: Model indices. 


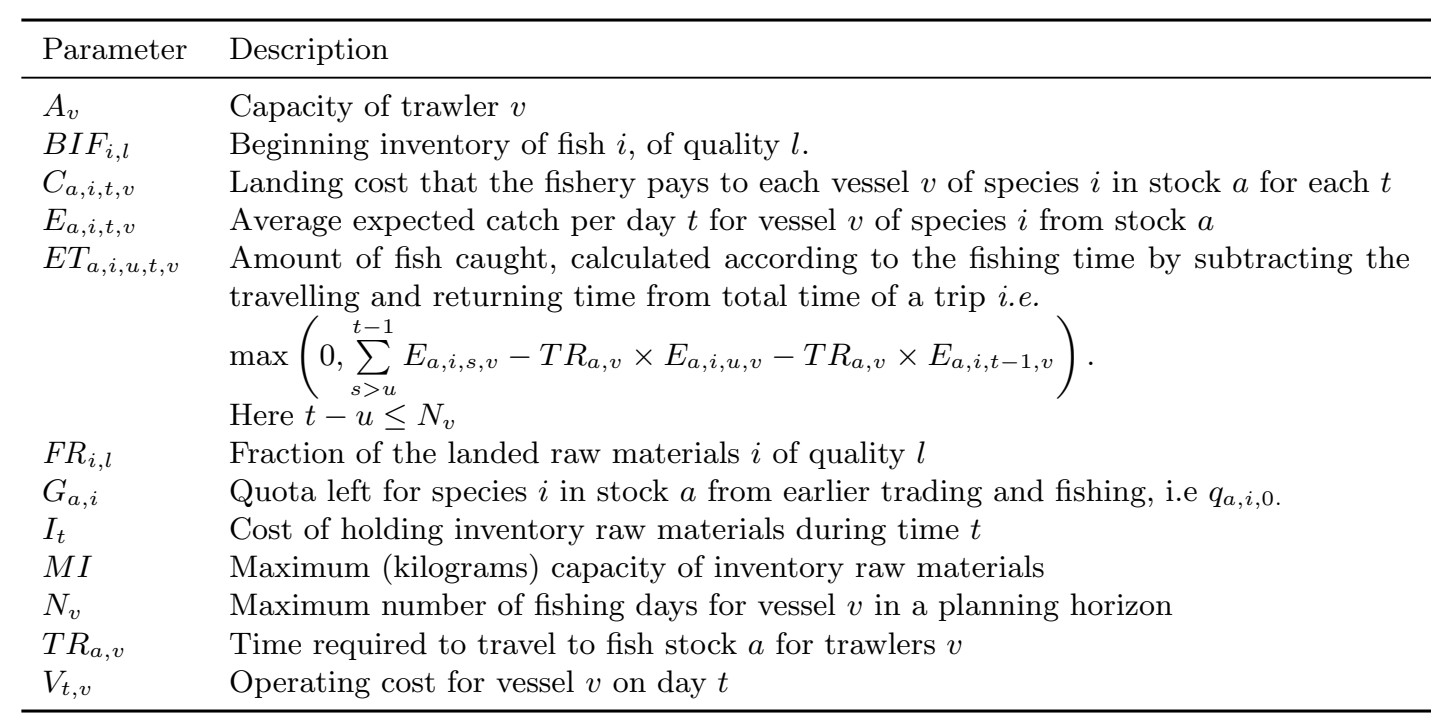

Table 2: Fishing parameters.

\begin{tabular}{ll}
\hline Parameter & Description \\
\hline$B I P_{i, j, l}$ & Beginning inventory product of species $i$, product $j$, quality $l$ \\
$F_{i, j}$ & Fillet percentage of raw material, i.e. kilogram of fish species $i$ required to produce 1 \\
& kilogram of product $j$ \\
$F R_{i, l}$ & Fraction of fish species $i$ of quality $l$ \\
$H_{i, j, c}$ & Working times (labour hours) required in work centre $c$ per kilogram fish $i$ in product $j$ \\
$J_{t}$ & Inventory holding cost of a product for period $t$ \\
$L r$ & Labour cost per hour for regular time \\
$L o$ & Labour cost per hour for overtime (the overtime labour rate is $25 \%$ higher than the \\
& regular time labour rate) \\
$L A r_{t}$ & Lower bound on regular labour hours in period $t$ \\
$L R_{i, l, t}$ & Lower bounds on kilograms of raw material $i$ of quality $l$ to be processed in period $t$ \\
$M I P$ & Storage capacity of maximum inventory product \\
$P_{i, j, l}$ & Profit of processing plant $j$ for raw material $i$, of quality $l$ (i.e. the weighted net sales \\
$R t$ & price of product $j$ for raw material less all variable costs, except labour cost) \\
$U A r_{t}$ & Ratio of overtime labour hours \\
$U M_{i, j, l, t}$ & Available regular labour hours in period $t$ \\
$U R_{i, l, t}$ & Upper bounds on kilograms of product $j$ of quality $l$ sold from raw material $i$ for \\
\hline
\end{tabular}

Table 3: Processing parameters. 


\begin{tabular}{ll}
\hline Variable & Description \\
\hline$f_{a, i, l, t, v}$ & Kilograms of fish species $i$ of quality $l$ from stock $a$ landed by trawler $v$ during period \\
& $t$ \\
$q_{a, i, t}$ & Quota kilograms of species $i$ from stock $a$ left over as available quota for period $t$ \\
$r_{i, j, l, t}$ & Kilograms of product $j$ made from species $i$ of quality $l$ kept in inventory at the end \\
& of planning horizon $t$ (we define $r_{i, j, l, 0}$ as the initial inventory, a constant) \\
$s_{i, j, l, t}$ & Kilograms of product $j$ sold from raw material $i$ of quality $l$ during period $t$ \\
$w_{p, a, u, t, v}$ & 1 if trawler $v$ steams from the firm $p$ to fish stock area $a$ during period $u$ for fishing and \\
& returns in period $t ; 0$ otherwise, for all $t=1, \ldots, T$, and all $u$ such that $t-u \leq N_{v}$, \\
& and all $v$ \\
$w_{t, v}$ & 1 if trawler $v$ waits in port during period $t ; 0$ otherwise \\
$x_{i, j, l, t}$ & Kilograms of product $j$ produced from raw material $i$ of quality $l$ in period $t$ \\
$y o_{t, c}$ & Overtime labour hours used in work centre $c$ during period $t$ \\
$y r_{c}$ & Regular labour hours used in work centre $c$ during period $t$ \\
$z_{i, l, t}$ & Kilograms of fish species $i$ kept in inventory at the end of planning horizon $t$ (we \\
& define $z_{i, l, 0}$ as the initial inventory, a constant) \\
\hline
\end{tabular}

Table 4: Model decision variables.

\subsection{Objective function}

Our objective is to maximize total profi, that is revenue from sales, less fishing cost, less production cost, less inventory holding cost. We therefore maximize the expression

$$
\begin{aligned}
& \sum_{i} \sum_{j} \sum_{l} \sum_{t} P_{i, j, l} s_{i, j, l, t}-\sum_{p} \sum_{a} \sum_{u} \sum_{t} \sum_{v} V_{t, v} w_{p, a, u, t, v}-\sum_{i} \sum_{l} \sum_{t} \sum_{v} \sum_{a} C_{a, i, t, v} f_{a, i, l, t, v} \\
& -\sum_{t} \sum_{c} L r_{t} y r_{c}-\sum_{t} \sum_{c} L o y o_{t, c}-\sum_{i} \sum_{l} \sum_{t} I_{t} z_{i, l, t}-\sum_{i} \sum_{j} \sum_{l} \sum_{t} J_{t} r_{i, j, l, t} .
\end{aligned}
$$

\subsection{Constraints}

A capacity constraint denotes that trawler $v$ can go to one fishing area $a$ at a time, and the amount of fish caught should not exceed the capacity $A_{v}$ of each trawler $v$. That is

$$
\sum_{i} \sum_{l} f_{a, i, l, t, v} \leq A_{v} \quad \text { for all } a, v \text { and } t .
$$

When calculating the landed fish, we employ a binary variable $w_{p, a, u, t, v}$ indicating whether a trawler goes for fishing or not. If a trawler goes for fishing, it will land its fish according to the quality of fish. Hence we have

$$
f_{a, i, l, t, v}=\sum_{u} E T_{a, i, u, t, v} \times F R_{i, l} \times w_{p, a, u, t, v} \quad \text { for all } p, a, i, l, t \text { and } v .
$$

A trawler will go to fishing or stay at port according to the requirement and profitability of the fishery. That is

$$
\sum_{a} \sum_{t=2}^{N_{v}} w_{p, a, u, t, v}+w r_{1, v}=1 \quad \text { for all } p \text { and } v
$$


The flow constraint

$\sum_{a} \sum_{u=1}^{\max \left\{1, t-N_{v}\right\}} w_{p, a, u, t, v}+w r_{t-1, v}-w r_{t, v}-\sum_{a} \sum_{t 1=t+1}^{\min \left\{t+N_{v}, T\right\}} w_{p, a, t, t 1, v}=0 \quad$ for all $p$ and $v$

is also assumed, stating that if a trawler goes out for fishing, it must come back to land its catch. Bounds on raw material $i$ of quality $l$ in period $t$,

$$
L R_{i, l, t} \leq \sum_{j} F_{i, j} x_{i, j, l, t} \leq U R_{i, l, t} \quad \text { for all } i, l \text { and } t
$$

state that the amount of processed raw materials, should not exceed the available raw materials. An inventory balance constraint

$$
z_{i, l, t-1}+\sum_{a} \sum_{v} f_{a, i, l, t, v}-\sum_{j} F_{i, j} x_{i, j, l, t}=z_{i, l, t} \quad \text { for all } i, l \text { and } t
$$

indicates that fish species $i$ of quality $l$ which is not used for production during period $t$ is stored as inventory $\left(z_{i, l, t}\right)$ for use in the next planning horizon. Inventory storage limits for raw materials dictate that

$$
\sum_{i} \sum_{l} z_{i, l, t} \leq M I \quad \text { for all } t
$$

Marketing constraints on products, which indicate the amount of product sold, depends on the demands in the market. That is

$$
s_{i, j, l, t} \leq U M_{i, j, l, t} \quad \text { for all } i, j, l \text { and } t .
$$

An inventory products balance equation,

$$
r_{i, j, l, t-1}+x_{i, j, l, t}-s_{i, j, l, t}=r_{i, j, l, t} \quad \text { for all } i, j, l \text { and } t
$$

states that subtraction of the amount of product sold from the total inventory product obtained from last period and amount of product produced during the current period, yields inventory for next period. A storage capacity constraint of inventory products states that the amount of inventory products during period $t$ should not exceed the maximum storage capacity. Hence

$$
\sum_{i} \sum_{j} \sum_{l} r_{i, j, l, t} \leq M I P \quad \text { for all } t .
$$

The working time required for filleting, packing, freezing and stocking during period $t$ should not exceed the total available regular and overtime, i.e.

$$
\sum_{i} \sum_{j} \sum_{l} H_{i, j, c} x_{i, j, l, t}-y r_{t, c}-y o_{t, c} \leq 0, \quad \text { for all } t \text { and } c .
$$

Bounds on the amount of regular labour available during period $t$ take the form

$$
L A r_{t} \leq y r_{c} \leq U A r_{t} \quad \text { for all } t \text { and } c .
$$


Overtime labour should not exceed $25 \%$ of regular amount of labour. That is

$$
y_{t, c} \leq R t \times y r_{c} \quad \text { for all } t \text { and } c .
$$

The available quota must balance over time. Hence we have a constraint of the form

$$
q_{a, i, t-1}-\sum_{l} \sum_{v} f_{a, i, l, t, v}=q_{a, i, t} \quad \text { for all } a, i \text { and } t,
$$

which states that subtracting the amount of fish landed from the total available quota, we calculate the remaining quota for the next periods. Variables are required to be non negative, i.e. $x_{i, j, l, t}, s_{i, j, l, t}, r_{i, j, l, t}, y r_{c}, y o_{t, c}, f_{a, i, l, t, v}, w_{p, a, u, t, v}, w r_{t, v}, z_{i, l, t}, q_{a, i} \geq 0$. Finally, the decision variables

$$
w_{p, a, u, t, v}, w r_{t, v} \in\{0,1\}
$$

are required to have binary values.

\subsection{A sample solution}

An example solution of a 10-period model is presented below. In its first trip, trawler 1 goes for fishing to area 3 in period 1 and lands its catch in period 3 . Trawler 2 goes for fishing to area 3 in period 1 and lands its catch in period 4 . The details of trawler scheduling are shown in Figure 3. Starting with an initial inventory of raw materials at $25950 \mathrm{~kg}$, the model yields a total profit of $\$ 683692$ for the fishery.

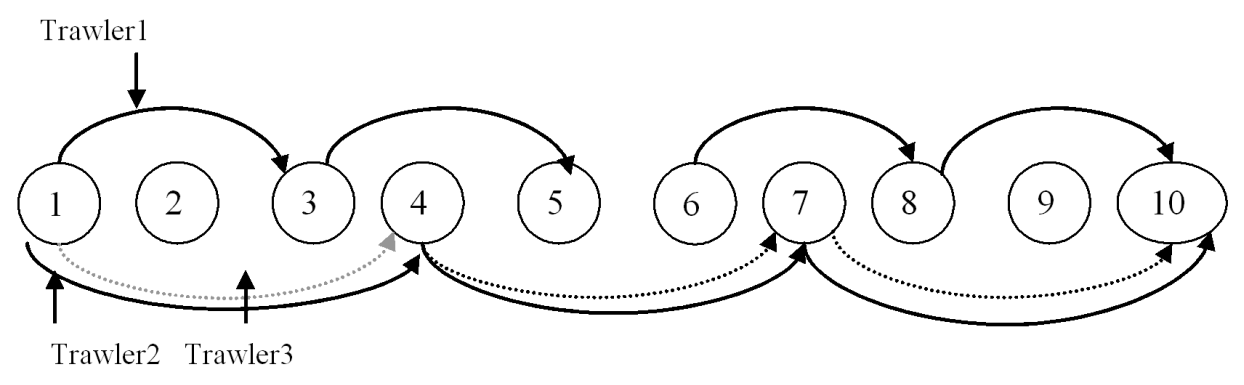

Figure 3: A sample fishing trawler scheduling for a 10-period model.

\section{Analysis of the model}

In this section, we describe a series of experiments designed to deal with the end effect of a planning horizon due to variability of catch rate, so as to observe why the model uses overtime and to observe the effect of variation of catch rate (from 10\% to 50\%) on profit. The aim of this sensitivity analysis is to gain knowledge about the structure and behaviour of our MILP model and to give additional information to the fishery so that it can develop guidelines for updating data and decision plans. 


\subsection{Safety stock for end-of-horizon effects due to variability of catch}

It is common practice that managers hold safety stocks to hedge against uncertainties in supply and demand. With a deterministic model, the planning manager may use a target final inventory.

Since the catch rate of each fish species varies for different reasons (such as weather conditions and seasons), the manager of the fishery should have a safety stock at the end of each planning horizon. The safety stock of raw materials may protect against stock-out problems due to incorrect catch forecasts, weather condition, seasons, etc. In real life, the manager of the integrated fishery typically uses a target final inventory after the end of each planning horizon to deal with the end-of-planning-horizon effects. In our model, we set a constraint which ensures that the beginning inventory of raw materials equals the final inventory. The constraint takes the following form

$$
z_{i, l, 0}=z_{i, l, T} \quad \text { for all } i, l \text { and } t .
$$

The model decides how much raw material will be kept as inventory at the end of a planning horizon. This is a type of safety stock which protects against variability created by the trawler schedule (man-made variability). The safety stock balances the inventory holding cost and the idle time.

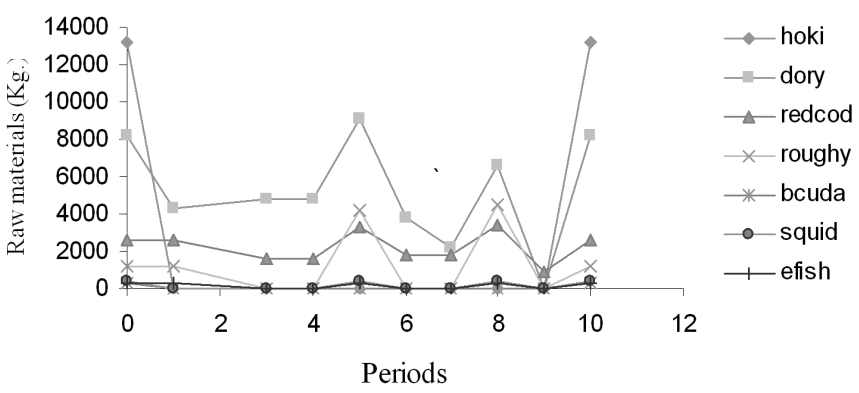

Figure 4: Inventory raw materials of each species in different periods.

For example, if a 10-period model is solved, we observe that the solution has a total of 80753 kilograms of beginning and final inventory raw materials as safety stock. It yields a total profit of $\$ 742976$. The results are shown in Figure 4 . It shows that the inventory raw materials vary throughout the planning horizon, but the beginning and the end inventory raw materials of each species remain the same.

The 10-period model balances inventory holding cost and uses no overtime and no idle time. However, for some planning horizons it uses overtime. For example, solving a 15period model we notice 77 hours of overtime, in a 16-period model we observe 265 hours of overtime and in 18-period model we notice 125 hours of overtime. With the increase of planning horizon, the number of overtime hours does not increase monotonically. The number of overtime hours used by a model depends on the length of planning horizon, trawler landings and the amount of raw materials available in different periods, regular and idle hours. Considering all of these, our model first decides how much regular labour 
is required per period for the entire planning horizon and then decides the amount of overtimes for different periods. The details of the results are shown in Table 5 .

\begin{tabular}{crr}
\hline $\begin{array}{c}\text { Length of } \\
\text { planning horizon }\end{array}$ & $\begin{array}{r}\text { Regular labour } \\
\text { per period }\end{array}$ & $\begin{array}{r}\text { Overtime in the } \\
\text { planning horizon }\end{array}$ \\
\hline 10-periods & 998 & 0 \\
14-periods & 1036 & 0 \\
15-periods & 1102 & 77 \\
16-periods & 1060 & 265 \\
17-periods & 1117 & 24 \\
18-periods & 1067 & 125 \\
20-periods & 1077 & 210 \\
\hline
\end{tabular}

Table 5: Regular and overtime labour used for different planning horizons.

\subsubsection{Setting inventory naively}

Instead of creating safety stock using the model, if we naively set beginning inventory raw material, the deterministic model will yield lower or higher profit depending on the amount of initial inventory raw materials. The higher the beginning inventory the higher the profit. To observe this, we considered solving the model with an initial inventory raw material of $25950 \mathrm{~kg}$. We noticed that, in period 1 the fishery uses 522 hours of labour, but in period 3 the fishery uses 1288 hours of labour, since it achieves first landings in period 3. Our 10-period deterministic model fixed 1030 hours as regular labour, and for each period from period 3 onwards, it uses different amounts of overtime labour for different period. We observe that in periods 3,7 and 9 the fishery achieves two landings each. Therefore higher overtime occurs in these periods, as shown in Figure 5. The model yields a total of $\$ 683692$ profit.

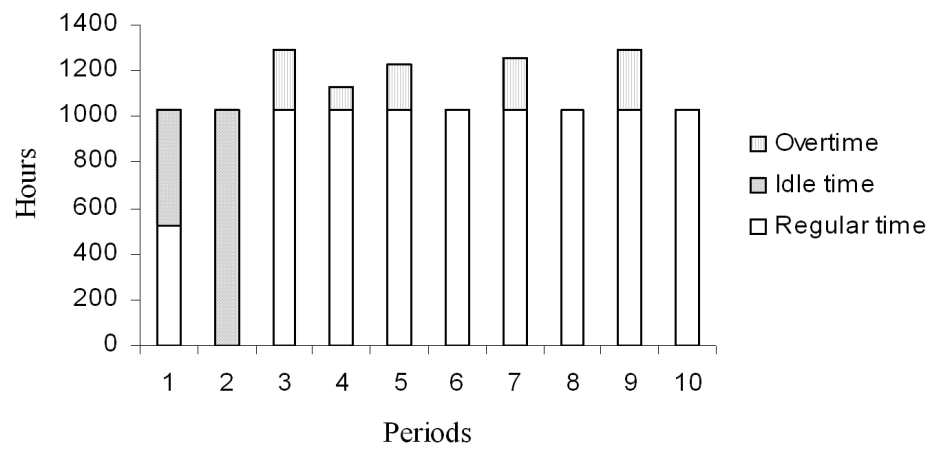

Figure 5: Comparison of total time, regular time, overtime and idle time that occurs in model solutions.

Using zero initial inventory raw materials, we observe that the model yields a profit of $\$ 665518$ and using $150000 \mathrm{~kg}$ of initial inventory row materials (maximum storage capacity), the model yields $\$ 734951$. In $\S 5.1$ we saw that the safety stock approach yields $\$ 742976$. 
Comparing the safety stock approach to naively setting inventory, we arrive at two conclusions. First, since the safety stock model calculates the beginning inventory raw materials, the profit is higher than that of naively setting beginning inventory raw materials. Second, changing the number of periods of the planning horizon for both of the above cases, we solved our deterministic model and observed that it uses some small amount of overtime. Hence it is clear that, in order to deal with the landed catch, inventory, storage capacity and market demand, a good deterministic model may use some overtime.

\subsubsection{Rolling horizon approach}

For the production plan, the model is solved for a number of periods and the solution is implemented. Then the model horizon is rolled forward to the point where the next decision has to be made, the new problem is solved, and the new decision is implemented. In this way, a decision plan is constructed for the true horizon of the fishery. The procedure of updating forecasts and solving the problem periodically is referred to as a rolling horizon approach. A rolling horizon approach (Blackburn and Millen (1980), Wagner and Whitin (1958)) is a strategy for managing the end effect of a planning horizon and the effect of uncertainty.

To deal with this end-of-planning horizon-effect using rolling horizon approach, the solution of a 10-period model may be repeated every five periods, since the first five periods are more certain than the last five periods. Then the parameters may be updated according to the solution obtained from the first stage and the model solved for the second stage of two stage mixed integer linear program.

\subsection{Effects of moving employees among work-centre on the profit}

If the employee can work in any work centre, then the fishery can reduce overtime. To verify this, we calculated the total time required to produce a product and to pack it by adding labour time in different centres for each product. We removed the work centres subscripts and modelled the work hours by means of the constraint

$$
\sum_{i} \sum_{j} \sum_{l} H_{i, j} x_{i, j, l, t}-y r-y o_{t} \leq 0 \quad \text { for all } t .
$$

The amount of regular labour available during period $t$ is given by

$$
L A r_{t} \leq y r \leq U A r_{t} \quad \text { for all } t
$$

Bounds on the amount of overtime labour are set as

$$
y o_{t} \leq R t \times y r \quad \text { for all } t,
$$

where $R t$ is the percentage of regular hours available for overtime hours. Overtime hours may not exceed $25 \%$ of the number of regular hour.

We notice that the model without work-centres subscripts uses 35 hours less overtime hours than the model with work-centre subscripts. We also observe that the model without 
work-centres subscripts yields $\$ 742976$ which is $(\$ 742976-\$ 741849)=\$ 1127$ higher profit $(0.2 \%)$ than that of the model with work-centres subscripts. We conclude that if the employees can work in any work centre, the fishery can yield slightly higher profits.

\subsection{Sensitivity of profit due to variability of catch}

Catch rate is the most important parameter which influences the trawler schedule and processing. Considering the last twenty years' catch rates (Clement, 2004), we determined the average expected catch for our MILP model. To observe the effect of catch variability on the profit, we used a normal distribution with five different coefficients of variation from $10 \%$ to $50 \%$ in order to generate five groups of catch rate parameters. For each coefficient of variation, we solved the model ten times and calculated the profit. The results are shown in Table 6 . The percentage change in profit is defined as

$$
100 \times \frac{\text { Deterministic solution }- \text { Solution with coefficient of variation }}{\text { Deterministic solution }} .
$$

Here the deterministic solution yields a profit of $\$ 742976$ which is obtained from $\S 5.1$. We notice a general decrease in the profit as variability of catch rate increases. However, the loss in profit is not monotonic. We also notice that the average profit lost for these five groups of catch rates is $4.15 \%$, which is approximately a $\$ 30000$ average decrease in profit.

\begin{tabular}{|c|c|c|c|c|c|}
\hline Coefficient of variation & 0.1 & 0.2 & 0.3 & 0.4 & 0.5 \\
\hline \multicolumn{6}{|c|}{ Profit } \\
\hline Run number & $\$ \times 10^{5}$ & $\$ \times 10^{5}$ & $\$ \times 10^{5}$ & $\$ \times 10^{5}$ & $\$ \times 10^{5}$ \\
\hline 1 & 7.41 & 7.12 & 7.11 & 5.68 & 5.64 \\
\hline 2 & 7.52 & 7.37 & 7.27 & 7.48 & 6.86 \\
\hline 3 & 7.46 & 7.46 & 7.33 & 7.57 & 7.46 \\
\hline 4 & 7.31 & 7.09 & 7.16 & 7.59 & 7.02 \\
\hline 5 & 7.4 & 7.16 & 7.51 & 6.16 & 7.06 \\
\hline 6 & 7.33 & 7.19 & 6.4 & 7 & 6.43 \\
\hline 7 & 7.59 & 6.86 & 6.85 & 6.6 & 6.81 \\
\hline 8 & 7.51 & 7.34 & 7.04 & 7.03 & 6.98 \\
\hline 9 & 7.44 & 7.53 & 7.3 & 7.02 & 7.73 \\
\hline 10 & 7.32 & 7.51 & 7.37 & 6.73 & 6.95 \\
\hline Average of 10 runs & 7.429 & 7.263 & 7.134 & 6.886 & 6.894 \\
\hline$\%$ profit loss & $0.01 \%$ & $2.25 \%$ & $3.98 \%$ & $7.32 \%$ & $7.21 \%$ \\
\hline
\end{tabular}

Table 6: Effect of variability of catch on profit.

\subsection{Computation times}

We implemented our model using the AMPL modelling language (Fourer et al., 1993) and used CPLEX to solve it. Varying the number of periods of the planning horizon from 8 to 20, we solved our model on a computer with an Intel Pentium III processor with a clock speed of $665 \mathrm{MHz}$ and $384 \mathrm{MB}$ of RAM. Table 7 shows the computation times, number of variables and number of constraints associated with each planning horizon length. 


\begin{tabular}{cccc}
\hline $\begin{array}{c}\text { Periods of the } \\
\text { planning horizon }\end{array}$ & $\begin{array}{c}\text { Computation time } \\
\text { (seconds) }\end{array}$ & Variables & Constraints \\
\hline 8 & 5 & 3513 & 3040 \\
9 & 5 & 3965 & 3409 \\
10 & 10 & 4423 & 3778 \\
11 & 15 & 4887 & 4147 \\
12 & 19 & 5357 & 4416 \\
13 & 16 & 5833 & 4885 \\
14 & 34 & 6315 & 5254 \\
15 & 43 & 6803 & 5623 \\
19 & 723 & 8815 & 7099 \\
20 & 950 & 9333 & 7468 \\
\hline
\end{tabular}

Table 7: The computational times, number of variables and number of constraints associated with each planning horizon length.

\section{Conclusion}

In this paper we developed a MILP model to schedule fishing trawlers and to plan production for an integrated commercial fishery. The model co-ordinates trawler scheduling, fishing, catch quota allocations, processing and labour allocation of fisheries. The output of the model suggests when and where a trawler should go for fishing, how much raw materials should be landed, what amount of product should be produced and how much regular and overtime labour hours are required. Changing different parameters such as beginning inventory raw materials, end effect of planning horizon, overtime, idle time and work centre, we also carried out a range of sensitivity analysis. The fishery can develop guidelines for updating data and decision plans in the light of new information obtained from this sensitivity analysis. So considering the decision environment in which our MILP model is to be implemented, the role of this sensitivity analysis is important. We also discussed end-effect-of-planning-horizon due to variability of catch rate and ways to deal with them. We hope that, given the complexity of the fishery problem and the level of uncertainty in the catch rate, the MILP model will provide an efficient approach to address the decisions to be made by the fishery.

\section{References}

[1] Blackburn JD \& Millen RA, 1982, The impact of a rolling schedule in a multi level MRP system, Journal of Operations Management, 2, pp. 125-135.

[2] Clement, 2004, New Zealand commercial fisheries: The atlas of area codes and TACCs, Clement \& Associates Ltd., Nelson.

[3] Clement, 2004, New Zealand commercial fisheries: The guide to the quota management system, Clement \& associates ltd., Nelson.

[4] Digernes T, 1982, Simple computation models for calculating profitability of fishing vessels, pp. 173-186, in HALEY KB (ED.), Applied Operations Research in Fishing, Proceedings of The NATO Symposium, Trondheim. 
[5] Fourer R, Gay DM \& Kernighan BW, 1993, AMPL: A modelling language for mathematical programming, Curt Hinrichs, Pacific Grove (CA) [also online available from http://www.ampl.com/].

[6] Gunn EA, Millar HH \& Newbold SM, 1991, A model for planning harvesting and marketing activities for integrated fishing firms under and enterprise allocation scheme, European Journal of Operational Research, 55, pp. 243-259.

[7] Helgason TH \& Olafsson S, 1988, An Icelandic fisheries model, European Journal of Operational Research, 33, pp. 191-199.

[8] Jensson P, 1979, A simulation model of the capelin fishing in Iceland, pp. 187-198, in Haley, K.B. (ED.), Applied operations research in fishing, Proceedings of The NATO Symposium, Trondheim.

[9] Jensson P, 1988, Daily production planning in fish processing firms, European Journal of Operational Research, 36, pp. 410-415.

[10] Jensson P, 1990, Co-ordination of fishing and fish processing, Unpublished Report, Engineering Faculty, University of Iceland, Reykjavik.

[11] Marielle C \& Fagerholt K, 2002, Ship routing and scheduling status and trends, Working Paper, Norwegian University of Science and Technology, Trondheim.

[12] Mikalsen B \& Vassdal T, 1981, A short term production planning model in fish processing, pp. 223-233, in HALEY KB (ED.), Applied operations research in fishing, Plenum Press, New York (NY).

[13] Millar HH \& GunN EA, 1992, A two-stage approach to planning harvesting and marketing activities integrated fishing enterprises, Fisheries Research, 15, pp. 197-215.

[14] Newell RG, Sanchirico JN \& Kerr S, 2002, An empirical analysis of New Zealand's ITQ market, Resources for the Future, Washington, DC, MOTU Economic and Public Research Trust, Wellington.

[15] New Zealand Official Yearbook, 2004/2005, New Zealand Goverment, Wellington.

[16] Randhawa SU, 1994, Integrating simulation and optimization: An application in fish processing industry, pp. 1241-1247 in TEW JD, Manivannan S, SADOWski DA, \& Seila AF (Eds.), Proceedings of the Winter Simulation Conference, Piscataway (NJ).

[17] Statistics New Zealand, 2003, Physical flow account for fish resources in New Zealand, [Online], [Cited: 1 February 2005], Available from www.stats.govt.nz/default.htm

[18] Wagner HM \& Whitin TM, 1958, Dynamic version of the economic lot size model, Management Science, 5, pp. 89-96. 